The fast emergency vehi cle pre-empt i on system i mproved the out comes of out- of-hospi t al cardi ac ar rest

\begin{tabular}{|l|l|}
\hline 著者 & $\begin{array}{l}\text { Tanaka Yoshi o, Yamada H r oshi, Tamasaku Shuj i , } \\
\text { I naba H deo }\end{array}$ \\
\hline $\begin{array}{l}\text { j our nal or } \\
\text { publ i cat i on ti t l e }\end{array}$ & Amer i can Jour nal of Ener gency Nedi ci ne \\
\hline vol une & 31 \\
\hline number & 10 \\
\hline page r ange & $1466-1471$ \\
\hline year & $2013-10-01$ \\
\hline URL & ht t p: //hdl . handl e. net /2297/35643 \\
\hline
\end{tabular}


The Fast Emergency Vehicle Pre-emption System Improved the Outcomes of Out-of-hospital

\section{Cardiac Arrest}

Short title: OHCA outcomes improved by FAST ${ }^{\mathrm{TM}}$

Yoshio Tanaka, MD, MSc

Department of Emergency Medical Science, Kanazawa University Graduate School of Medicine

Hiroshi Yamada

Kanazawa city Fire Department

Shuji Tamasaku

Kanazawa city Fire Department

Hideo Inaba, MD, PhD

Professor and Chairman

Department of Emergency Medical Science, Kanazawa University Graduate School of Medicine

Reprint requests: Hideo Inaba, Department of Emergency Medical Science,

Kanazawa University Graduate School of Medicine 13-1 Takara-machi, Kanazawa, Ishikawa,

920-8641, Japan

Phone +81 76-265-2825 Fax +81 76-234-4243 Email: hidinaba@med.kanazawa-u.ac.jp

Name of grant: None. 
A part of the work described in the manuscript has been formally poster presented in English at the “31 ${ }^{\text {st }}$ International Symposium on Intensive Care and Emergency Medicine” March 22-25, 2011 and oral presented in Japanese at "The $39^{\text {th }}$ annual meeting of the Japanese Association for Acute Medicine” October 20, 2011.

Keywords: ambulance response time; out-of-hospital cardiac arrest; traffic control system; emergency medical service

Total word count: 2639, Number of tables: 3, Number of figures: 2, Number of references: 33

Corresponding author:

Hideo Inaba, MD, PhD Professor and Chairman

Department of Emergency Medical Science,

Kanazawa University Graduate School of Medicine

13-1 Takara-machi, Kanazawa, 920-8641, Japan

Phone +81 76-265-2825

Fax +81 76-234-4243

Email: hidinaba@med.kanazawa-u.ac.jp 


\section{Abstract}

Purposes: Ambulance response time is a major factor associated with survival in out-of-hospital cardiac arrests (OHCAs); the fast emergency vehicle pre-emption system $\left(\mathrm{FAST}^{\mathrm{TM}}\right.$ ) aids response time by controlling traffic signals. This eight-year observational study investigated whether FAST $^{\mathrm{TM}}$ implementation reduced response times and improved OHCA outcomes.

Methods: Data was prospectively collected from 1161 OHCAs that were not witnessed by emergency medical technicians (EMTs) from April 1, 2003 to March 31, 2011. The study took place in Kanazawa city, where ambulances without $\mathrm{FAST}^{\mathrm{TM}}$ (non- $\mathrm{FAST}^{\mathrm{TM}}$-equipped) were being progressively replaced by new $\mathrm{FAST}^{\mathrm{TM}}$-equipped ambulances. OHCA data, including the response times recorded in seconds, were collected and compared between the $\mathrm{FAST}^{\mathrm{TM}}$-equipped and non- $\mathrm{FAST}^{\mathrm{TM}}$-equipped ambulances. OHCA outcomes were subsequently compared in the subgroup of OHCAs managed by EMTs without tracheal intubation or epinephrine administration. The primary end-point of this study was one-year (1-Y) survival.

Results: The median response time significantly differed between the FAST ${ }^{\mathrm{TM}}$-equipped and non$\mathrm{FAST}^{\mathrm{TM}}$-equipped groups at 327 and $381 \mathrm{~s}$, respectively. The 1 -Y survival rates were $7.0 \%$ in the $\mathrm{FAST}^{\mathrm{TM}}$-equipped group and $2.8 \%$ in the non- $\mathrm{FAST}^{\mathrm{TM}}$-equipped group. Logistic regression analysis revealed that the dispatch of a $\mathrm{FAST}^{\mathrm{TM}}$-equipped ambulance was an independent factor for 1-Y survival (adjusted odds ratio $=3.077,95 \%$ confidence interval $=1.180-9.350$ ).

Conclusions: The FAST ${ }^{\mathrm{TM}}$ implementation significantly reduced ambulance response times and improved OHCA outcomes in Kanazawa city. (Word count: 231) 


\section{Introduction}

The response time, defined as the interval between call for and arrival of an ambulance, is one of the major factors associated with favorable outcomes of out-of-hospital cardiac arrests (OHCAs) [1, 2]. Although reducing the response time may improve OHCA outcomes [3-7], there are only a few ways to achieve it. For example, response times can be improved by increasing the number of ambulance teams and fire department offices, or by equipping additional first-line responders with defibrillators, such as the fire fighters and police services [8, 9].

The fast emergency vehicle pre-emption system is a component of the universal traffic control system (UTMS) used in Japan, and is officially termed FAST ${ }^{\mathrm{TM}}$ by the UTMS society of Japan [10]. FAST ${ }^{\mathrm{TM}}$ minimizes emergency vehicle transit time by controlling traffic signals [11], thereby offering a potential approach to reduce ambulance response times. However, the effect of $\mathrm{FAST}^{\mathrm{TM}}$ on OHCA outcomes has not been investigated to date. This study therefore aimed to determine whether the implementation of $\mathrm{FAST}^{\mathrm{TM}}$ reduced ambulance response times and, in turn, improved outcomes.

\section{Methods}

An eight-year prospective, observational study was designed to evaluate the impact of $\mathrm{FAST}^{\mathrm{TM}}$ implementation on the emergency medical service (EMS) response times and OHCA outcomes. All data were collected in accordance with the national guideline of ethics for epidemiological surveys [12]. This study was approved by a review board at the Ishikawa Medical Control Council. 


\section{Patient data}

Kanazawa city Fire Department prospectively collected data in accordance with the Utstein recommendation [13, 14]. In central Kanazawa city, data for all OHCAs with attempted resuscitation and those who were transported to hospitals were collected from April 1, 2003 to March 31, 2011. The following data were collected: region; arrest location; patient age and gender; witness of arrest; arrest etiology; cardiopulmonary resuscitation (CPR) before emergency medical technician (EMT) arrival; initial cardiac rhythm; various time factors including response time and duration of transportation to hospital (defined as the time interval between ambulance departure from the arrest scene and arrival at hospital); sustained return of spontaneous circulation (SROSC); one-year (1-Y) survival; and 1-Y survival with a favorable neurological outcome (cerebral performance score $=1$ or 2 ) [15]. SROSC was defined as the continuous presence of palpable pulses for at least 20 min [13, 14]. Survival at 1-Y was defined as being alive in the hospital at $1-\mathrm{Y}$ or discharged alive from the hospital to home or to care and rehabilitation facilities within 1-Y. The primary end point was 1-Y survival. The secondary end points were SROSC and 1-Y survival with a favorable neurological outcome.

\section{Populations and setting}

Kanazawa city, the capital of Ishikawa Prefecture, covers $468 \mathrm{~km}^{2}$ on the western coast of Honshu, the main island of Japan, and has a population of 461,700. The city is a historical castle town, and the streets in the central area are often congested. The city has eight ambulance stations, each with a one-tiered ambulance system controlled by a single dispatch center and the same level of EMT team is dispatched to all emergency cases. The number of dispatched cases (number of dispatch to 
OHCAs/total dispatch) during the study period was 224/11951 (1.9\%) in 2003 (fiscal year beginning on April 1); $204 / 12870$ (1.6\%) in 2004; 206/12894 (1.6\%) in 2005; 210/13328 (1.6\%) in 2006; $223 / 14155$ (1.6\%) in 2007; 247/13694 (1.8\%) in 2008; 302/13890 (2.1\%) in 2009; and 273/13942 $(2.0 \%)$ in 2010.

Telephone-assisted CPR instruction was regularly and strictly conducted by a dispatcher.

EMTs resuscitated OHCA patients according to the protocol developed by the Ishikawa Medical Control Council from the guidelines of the American Heart Association and the Japan Resuscitation Council, unless OHCA patients had post-mortem changes. Paramedics were included in all ambulance teams and were authorized to perform the following procedures during resuscitation: (a) use of airway adjuncts, including the suprapharyngeal airway or laryngeal mask airway, (b) infusion of Ringer's lactate through a peripheral vein, and (c) use of semi-automated external defibrillators. Since July 2004, specially trained paramedics have been permitted to insert endotracheal tubes, and since April 2006, they have been permitted to administer intravenous epinephrine. Strict criteria limited the use of these pre-hospital advanced cardiac life support (ACLS) procedures (Table 1) [16]. EMTs are not permitted to terminate resuscitation in the field.

\section{Fast emergency vehicle pre-emption system}

FAST $^{\mathrm{TM}}$ is one component of the UTMS [10] that minimizes the transit time of emergency vehicles by controlling traffic signals; an animated presentation, demonstrating $\mathrm{FAST}^{\mathrm{TM}}$ can be seen on the UTMS website [11]. The system includes an infrared beacon that recognizes emergency vehicles on the road and a traffic signal control unit. These components were installed on trunk roads 
in the central Kanazawa city at the beginning of 2003. However, to activate FAST ${ }^{\mathrm{TM}}$, emergency vehicles need to be equipped with an infrared beacon. In response to the increase in the length of $\mathrm{FAST}^{\mathrm{TM}}$-implemented trunk roads, the fire department progressively replaced old non-FAST ${ }^{\mathrm{TM}}$-equipped ambulances with newer $\mathrm{FAST}^{\mathrm{TM}}$-equipped ambulances (Table 1). All ambulances in the central Kanazawa city had been loaded with the FAST ${ }^{\mathrm{TM}}$ equipment for the observation period. The new ambulances had lower horsepower to weight ratios than the old ambulances due to an increased demand to reduce fuel costs. In total, 48 traffic signals on trunk roads, at a total length of $12.6 \mathrm{~km}$, were under the control of $\mathrm{FAST}^{\mathrm{TM}}$ in the central Kanazawa city and most major emergency hospitals were located in this area (Figure 1).

$\mathrm{FAST}^{\mathrm{TM}}$ does not modify traffic signals every time an ambulance passes; its function is controlled by integrated traffic control systems that are informed by current traffic conditions. Previous traffic engineering studies [17] revealed that $\mathrm{FAST}^{\mathrm{TM}}$ activated at a rate of $91.2 \%$ when ambulances passed FAST ${ }^{\mathrm{TM}}$-controlled signals. Of the ambulances dispatched from the central area, 68.8\% passed FAST $^{\mathrm{TM}}$-controlled signals.

\section{Statistical analysis}

The data for all OHCAs unwitnessed by EMTs in the central area were compared between the $\mathrm{FAST}^{\mathrm{TM}}$ - and non-FAST ${ }^{\mathrm{TM}}$ - equipped ambulances, which individually comprised two groups. The control group was OHCA cases to which non-FAST ${ }^{\mathrm{TM}}$-equipped ambulances were dispatched. We analyzed the effect of FAST ${ }^{\mathrm{TM}}$ installation on OHCA outcomes managed prior to hospital arrival without tracheal intubation or epinephrine administration because the incidences of these procedures 
widely differed between the two groups (Table 2).

We analyzed the data using the Joint Medical Program (JMP), version 9, for Windows

[Statistical Analysis System (SAS) Institute, Cary, NC, USA]. The chi-squared test with or without

Pearson's correction was applied for univariate analyses. The Wilcoxon rank sums test and the

Kruskal-Wallis test were used for non-parametric comparisons. One-way ANOVA was used for

parametric comparison. We used multiple logistic regression analysis to elucidate the factors

associated with the outcomes. In all analyses, $p<0.05$ was considered statistically significant.

\section{Results}

\section{Annual changes in FAST ${ }^{T M}$ installation, traffic conditions, and critical parameters (Table 1)}

The annual changes in OHCA outcomes, together with the various parameters related to them,

were compared over the eight years of the observational study. Table 1 demonstrates the significant changes in the incidences of tracheal intubation, epinephrine administration, response time, and 1-Y survival rates for OHCAs. An annual traffic survey at four intersections revealed that there were small, but significant changes in traffic volume (less than 10\%), over the study period.

In accordance with the introductions of tracheal intubation and epinephrine administration, the EMT protocol was revised. However, during the study period, it was continuously emphasized that EMTs should provide high-quality basic life support (BLS) for all OHCA patients.

\section{Background and time factor differences (Table 2)}


There were significant differences in both arrest location (home versus others) and patient gender between the $\mathrm{FAST}^{\mathrm{TM}}$ - and non-FAST ${ }^{\mathrm{TM}}$-equipped groups. However, no significant difference existed in the duration of transportation to hospital between $\mathrm{FAST}^{\mathrm{TM}}$ - and non-FAST ${ }^{\mathrm{TM}}$-equipped ambulances. The response time was significantly shorter and the incidence of response time under 300 s was significantly higher in the $\mathrm{FAST}^{\mathrm{TM}}$-equipped group. The median response times (25-75\%) were 327 (244-429) s in the FAST ${ }^{\mathrm{TM}}$-equipped group and 381 (291-487) $\mathrm{s}$ in the non-FAST ${ }^{\mathrm{TM}}$-equipped group. ACLS procedures, including tracheal intubation and epinephrine administration, occurred more frequently in OHCA patients transported by $\mathrm{FAST}^{\mathrm{TM}}$-equipped ambulances.

\section{Comparisons of OHCA outcomes managed without prehospital ACLS procedures between FAST ${ }^{T M}$ - and non-FAST ${ }^{T M}$-equipped ambulances (Figure 2)}

Because tracheal intubation and epinephrine administration have been shown to affect OHCA outcomes [16, 18-22] and because the incidences of these procedures widely differed between the two groups (Table 2), we analyzed the impact of FAST ${ }^{\mathrm{TM}}$ on the outcomes of OHCAs managed prior to hospital arrival without tracheal intubation or epinephrine administration.

As demonstrated in Figure 2, incidences of SROSC and 1-Y survival were significantly higher in the group with dispatch of $\mathrm{FAST}^{\mathrm{TM}}$-equipped ambulances for all OHCAs, OHCAs with a presumed cardiac etiology, and witnessed OHCAs with a presumed cardiac etiology. 


\section{(Table 3)}

As shown in Table 3, univariate analysis identified several factors associated with 1-Y

survival: dispatch with $\mathrm{FAST}^{\mathrm{TM}}$-equipped ambulance, patient age, location of cardiac arrest, witnessed cardiac arrest, arrests of a presumed cardiac etiology, and response time. Traffic volume, estimated from Table 1, was not a significant factor associated with 1-Y survival.

Multiple logistic analysis revealed that dispatch with a $\mathrm{FAST}^{\mathrm{TM}}$-equipped ambulance, patient age, a witnessed cardiac arrest, and cardiac arrests with a presumed cardiac etiology were independent factors associated with 1-Y survival. The location of arrest or the response time was not an independent factor associate with 1-Y survival. However, adjusted odds ratio (OR) of response time for 1 -Y survivals was 0.998 (95\% confidence interval $=0.996-0.999)$, when the factor of dispatch with FAST $^{\mathrm{TM}}$-equipped ambulance was excluded from the logistic regression analysis,

\section{Discussion}

Because the incidences of tracheal intubation and epinephrine administration significantly increased during the study period and differed between the two groups, we compared the outcomes between the two groups for those OHCAs managed without either tracheal intubation or epinephrine administration. This eight-year observational study in the central area of a single city showed that FAST $^{\mathrm{TM}}$ implementation in ambulances successfully reduced the median response time by $54 \mathrm{~s}$ in EMT-unwitnessed OHCAs and improved OHCA outcomes in the subgroup not receiving ACLS procedures. When assessing the OHCA subcategory of presumed cardiac etiology, the 
FAST $^{\mathrm{TM}}$-equipped ambulance was significantly associated with greater incidences of an initial shockable rhythm, SROSC, 1-Y survival, and 1-Y survival with a favorable neurological outcome.

Multiple logistic regression analysis followed by univariate analysis revealed that FAST $^{\mathrm{TM}}$-equipped ambulance dispatch, patient age, cardiac etiology, and arrest witness were independent factors associated with 1-Y survival. Although univariate analysis disclosed a significant difference in response time between 1-Y survivors and non-survivors, multiple logistic regression analysis revealed that the response time was not an independent factor with 1-Y survival. However, the response time was an independent factor associated with 1-Y survival when dispatch with $\mathrm{FAST}^{\mathrm{TM}}$-equipped ambulance was excluded from multiple logistic regression analysis. This difference was mostly due to the dependence of response time on the dispatch with FAST ${ }^{\mathrm{TM}}$-equipped ambulances, which was shown as the significantly reduced response time and augmented incidence of early arrival (response time $<300 \mathrm{~s}$ ( 5 min)) by the dispatch with $\mathrm{FAST}^{\mathrm{TM}}$-equipped ambulance in Table 2. Thus, the benefit of $\mathrm{FAST}^{\mathrm{TM}}$ implementation seems to be attributed, at least in part, to the reduced response time and/or incidence of arrival delay.

In contrast to response time, the transportation time widely varied and there was no significant difference in the transportation time between $\mathrm{FAST}^{\mathrm{TM}}$ - and non-FAST ${ }^{\mathrm{TM}}$-equipped ambulances. The nearest ambulance team is always dispatched to the scene, while the transportation is not always made to the closest hospital. This may explain the difference between the effects of FAST $^{\mathrm{TM}}$-equipped ambulance on the median values of two time intervals.

The absolute difference in the median response time between the $\mathrm{FAST}^{\mathrm{TM}}$ - and 
non-FAST ${ }^{\mathrm{TM}}$-equipped ambulances was $54 \mathrm{~s}$. This reduction may be too small to explain the improvement seen in outcomes. However, the adjusted unit OR of response time for 1-Y survival was $0.998(95 \%$ confidence interval $=0.996-0.999)$ when the factor of dispatch with $\mathrm{FAST}^{\mathrm{TM}}$-equipped ambulances was excluded from the logistic regression analysis, indicating that the reduction in response time by $1 \mathrm{~s}$ increases the $1-\mathrm{Y}$ survival rate by $0.2 \%$. It has been shown that the effect of reducing the response time on survival from OHCAs is prominent when the response time does not exceed 5 to 6 min $[5,23]$. Furthermore, a previous study showed that a short response time (less than 6 min) could lead to a high survival rate [24]. Reduced response time may be associated with an early application of first defibrillation that is related to the survival of OHCA patients having a shockable initial rhythm [25]. In this study, we showed that the incidence of response time less than $300 \mathrm{~s}$ (5 min) was significantly increased when transported by $\mathrm{FAST}^{\mathrm{TM}}$-equipped ambulances (Table 2). Thus, a large improvement in the 1-Y survival seemed to be achievable by dispatch with $\mathrm{FAST}^{\mathrm{TM}}$-equipped ambulances in the central area.

$\mathrm{FAST}^{\mathrm{TM}}$ has been implemented in Kanazawa city by the Police Department of Ishikawa Prefecture as a public enterprise. FAST ${ }^{\mathrm{TM}}$ has also been introduced in nine other cities and in the Tokyo metropolitan area in Japan. The exact cost of this initiative is unclear, but the Police Department of Ishikawa Prefecture has estimated that approximately 180 million yen (1.8 million USD) was spent to install the FAST ${ }^{\mathrm{TM}}$ communication system on trunk roads. In addition to the cost of installation on roads and in ambulances, the UTMS requires a traffic control center. The cost benefit of FAST $^{\mathrm{TM}}$ implementation remains to be clarified. 


\section{Limitations}

Immeasurable or unpredictable changes might have occurred during the study period, which might have affected our interpretation. Nevertheless, their impact might have been minimized by the gradual introduction of FAST ${ }^{\mathrm{TM}}$ equipment to ambulances between 2003 and 2011 (see Figure 1 and Table 1). All new ambulances equipped with a $\mathrm{FAST}^{\mathrm{TM}}$ beacon had a lower horsepower and weight ratio than the old ambulances due to an increased demand to reduce fuel costs. Therefore, it is unlikely that the newer $\mathrm{FAST}^{\mathrm{TM}}$-equipped ambulances benefitted from performance improvements. We also considered both the changes in traffic volume and the EMS level provided.

The EMS protocol changed several times during the study period, with major revisions made following the introduction of tracheal intubation and epinephrine administration. However, during the study period, it was continuously emphasized that EMTs should provide high-quality BLS for all OHCA patients. To remove the confounding effect of these changes, we also determined the significant factors associated with 1-Y survival in OHCAs managed without ACLS procedures (Table 3). This exclusion appeared acceptable but bias may have been introduced according to literature suggesting unfavorable influences on OHCA outcomes [26-29].

The traffic volume estimated from Table 1 did not significantly differ between survivors and non-survivors. No data on the quality of bystander CPR were collected in this study. Bystander CPR is a recognized factor in achieving good outcomes for OHCA patients [30, 31], and the lack of record could negatively affect our results.

A previous traffic engineering study estimated that installing FAST $^{\mathrm{TM}}$ equipment on 
ambulances increased driving speeds by $17.9 \mathrm{~km} / \mathrm{h}$ on $\mathrm{FAST}^{\mathrm{TM}}$-implemented roads [17]. However, the actual distance of the FAST ${ }^{\mathrm{TM}}$-implemented roads on which each ambulance drove was not known in this study. If this information were available for the entire observational period, a more in-depth analysis of this effect might be possible.

This study was a retrospective analysis of prospectively collected data from a single city in Japan. The data set analyzed might have been too small for accurate multiple logistic regression analysis. This limits the universality of this study, although the independent factors associated with survival in the present study were clearly comparable with those in previous, larger studies reported by us and others [32, 33].

\section{Conclusions}

This observational study in Kanazawa city showed that the FAST ${ }^{\mathrm{TM}}$ implementation significantly reduced ambulance response times and improved OHCA outcomes. However, a large, multi-region study is necessary to confirm the cost-benefit relationship for $\mathrm{FAST}^{\mathrm{TM}}$ implementation.

\section{References}

1. Vukmir RB. Survival from prehospital cardiac arrest is critically dependent upon response time.

Resuscitation. 2006;69:229-234.

2. Pons PT, Haukoos JS, Bludworth W, et al. Paramedic response time: does it affect patient survival? Acad Emerg Med. 2005;12:594-600. 
3. Pell JP, Sirel JM, Marsden AK, et al. Effect of reducing ambulance response times on deaths from out of hospital cardiac arrest: cohort study. BMJ. 2001;322:1385-8.

4. Do HQ, Nielsen SL, Rasmussen LS. Response interval is important for survival until admission after prehospital cardiac arrest. Dan Med Bull. 2010;57:A4203.

5. Sladjana A, Gordana P, Ana S. Emergency response time after out-of-hospital cardiac arrest.

Eur J Intern Med. 201;22:386-93.

6. Neukamm J, Gräsner JT, Schewe JC, et al. The impact of response time reliability on CPR incidence and resuscitation success: a benchmark study from the German Resuscitation Registry.

Crit Care. 2011;15:282.

7. Kitamura $\mathrm{T}$, Iwami $\mathrm{T}$, Kawamura $\mathrm{T}$, et al. Nationwide improvements in survival from out-of-hospital cardiac arrest in Japan. Circulation. 2012;126:2834-43.

8. Nichol G, Laupacis A, Stiell IG, et al. Cost-effectiveness analysis of potential improvements to emergency medical services for victims of out-of-hospital cardiac arrest. Ann Intern Med. 1996;27:711-20.

9. Lin CS, Chang H, Shyu KG, et al. A method to reduce response times in prehospital care: the motorcycle experience. Am J Emerg Med. 1998;16:711-3.

10. UTMS society of Japan.

(Accessed 5 March 2013, at http://www.utms.or.jp/english/system/index.html)

11. FAST (Fast Emergency Vehicle Preemption Systems).

(Accessed 5 March 2013, at http://www.utms.or.jp/english/system/fast.html) 
12. The Ministry of Health, Labour and Welfare in Japan. (Accessed 5 March 2013, at http://www.mhlw.go.jp/seisakunitsuite/bunya/hokabunya/kenkyujigyou/i-kenkyu/index.html)

13. Cummins RO, Chamberlain DA, Abramson NS, et al. Recommended guidelines for uniform reporting of data from out-of-hospital cardiac arrest: the Utstein Style. A statement for health professionals from a task force of the American Heart Association, the European Resuscitation Council, the Heart and Stroke Foundation of Canada, and the Australian Resuscitation Council. Circulation. 1991;84:960-75.

14. Jacobs I, Nadkarni V, Bahr J, et al. Cardiac arrest and cardiopulmonary resuscitation outcome reports: update and simplification of the Utstein templates for resuscitation registries: a statement for healthcare professionals from a task force of the International Liaison Committee on Resuscitation (American Heart Association, European Resuscitation Council, Australian Resuscitation Council, New Zealand Resuscitation Council, Heart and Stroke Foundation of Canada, Inter American Heart Foundation, Resuscitation Councils of Southern Africa). Circulation. 2004;23:3385-97.

15. A. Safar P. Resuscitation after Brain Ischemia, in Grenvik A and Safar P Eds: Brain Failure and Resuscitation. Churchill Livingstone, New York 1981;155-84.

16. Takei Y, Enami M, Yachida T, et al. Tracheal intubation by paramedics under limited intubation criteria may improve the short-term outcome of out-of-hospital cardiac arrests with noncardiac origin. J Anesth. 2010;24:716-25.

17. Takada K, Inaba H, Nanbu S. Effect of introducing a FAST Emergency Vehicle Preemption system in Kanazawa (in Japanese). IATSS Review. 2009;34:47-54. 
18. Stiell IG, Wells GA, Field B, et al. Advanced cardiac life support in out-of-hospital cardiac arrest.

N Engl J Med. 2004;351:647-56.

19. Olasveengen TM, Sunde K, Brunborg C, et al. Intravenous drug administration during out-of-hospital cardiac arrest: a randomized trial. JAMA. 2009;302:2222-9.

20. Studnek JR, Thestrup L, Vandevender S, et al. The association between prehospital endotracheal intubation attemps and survival to hospital discharge among out-of-hospital cardiac arrest patient.

Acad Emerg Med. 2010;17:918-25.

21. Jacobs IG, Finn JC, Jelinek GA, et al. Effect of adrenalin on survival in out-of-hospital cardiac arrest: A randomised double-blind placebo-controlled trial. Resuscitation. 2011;82:1138-43.

22. Nakahara S, Tomio J, Nishida M, et al. Association between timing of epinephrine administration and intact neurologic survival following out-of-hospital cardiac arrest in Japan: a population-based prospective observational study. Acad Emerg Med. 2012;19:782-92.

23. 2005 American Heart Association Guidelines for Cardiopulmonary Resuscitation and Emergency Cardiovascular Care Part 4: Adult Basic Life Support. Circulation. 2005;112:IV-19-IV-34.

24. O'Keeffe C, Nicholl J, Turner J, et al. Role of ambulance response times in the survival of patients with out-of-hospital cardiac arrest. Emerg Med J. 2011;28:703-6.

25. De Maio VJ, Stiell IG, Wells GA, et al. Optimal defibrillation response intervals for maximum out-of-hospital cardiac arrest survival rates. Ann Emerg Med. 2003;42:242-50.

26. Advanced airway management does not improve outcome of out-of-hospital cardiac arrest.

Hanif MA, Kaji AH, Niemann JT. Acad Emerg Med. 2010;17:926-31. 
27. Hasegawa K, Hiraide A, Chang Y, Brown DF. Association of prehospital advanced airway management with neurologic outcome and survival in patients with out-of-hospital cardiac arrest.

JAMA. 2013;309:257-66.

28. Holmberg M, Holmberg S, Herlitz J. Low chance of survival among patients requiring adrenaline (epinephrine) or intubation after out-of-hospital cardiac arrest in Sweden. Resuscitation. 2002;54:37-45.

29. Hagihara A, Hasegawa M, Abe T, et al. Prehospital epinephrine use and survival among patients with out-of-hospital cardiac arrest. JAMA. 2012;307:1161-8.

30. Gallagher EJ, Lombardi G, Gennis P. Effectiveness of bystander cardiopulmonary resuscitation and survival following out-of-hospital cardiac arrest. JAMA. 1995;274:1922-1925.

31. Wik L, Steen PA, Bircher NG. Quality of bystander cardiopulmonary resuscitation influences outcome after prehospital cardiac arrest. Resuscitation. 1994;28:195-203.

32. Takei Y, Inaba H, Yachida T, et al. Analysis of reasons for emergency call delays in Japan in relation to location: High incidence of correctable causes and the impact of delays on patient outcomes. Resuscitation. 2010;81:1492-8.

33. Holmberg M, Holmberg S, Herlitza J, et al. Survival after cardiac arrest outside hospital in Sweden. Resuscitation. 1998;36:29-36. 


\section{Legends for Figures/Tables}

\section{Figure legends}

Figure 1 Trunk roads with infrared beacons installed, and the location of ambulance teams and major emergency hospitals in Kanazawa city.

\begin{tabular}{|c|c|c|c|}
\hline Ambulance Team Number & $\underline{\text { Name of Team }}$ & $\underline{\text { Dispatch Area }}$ & $\underline{\text { Date of FAST }}{ }^{\mathrm{TM}} \underline{\text { Installation }}$ \\
\hline AT1 & Ekinishi & Central & July 28, 2003 \\
\hline AT2 & Chuo & Central & December 21, 2004 \\
\hline AT3 & Misogura & Central & March 16, 2007 \\
\hline AT4 & Izumino & Central & January 27, 2011 \\
\hline
\end{tabular}

AT-(number): ambulance team number.

H1: Ishikawa Prefecture Central Hospital. H2: Kanazawa Medical Center. H3: Kanazawa University Hospital

Figure 2 Crucial comparisons of outcomes between $\mathrm{FAST}^{\mathrm{TM}}$ - and non-FAST ${ }^{\mathrm{TM}}$-equipped ambulances for OHCAs managed without ACLS procedures.

The panels represent all OHCAs, OHCAs with a presumed cardiac etiology, and witnessed OHCAs with a presumed cardiac etiology. 
$\star \quad$ Significant difference between the dispatch with $\mathrm{FAST}^{\mathrm{TM}}$ - and non-FAST ${ }^{\mathrm{TM}}$-equipped

ambulances (by chi-squared test with Person's correction).

\section{Table legends}

Table 1 Annual changes in FAST ${ }^{\mathrm{TM}}$ installation, traffic conditions, and critical parameters.

* At the beginning of fiscal year.

Table 2 Differences in backgrounds, time factors, and the management of OHCAs between the dispatch with $\mathrm{FAST}^{\mathrm{TM}}$ - and non-FAST ${ }^{\mathrm{TM}}$-equipped ambulances.

* CPR first performed by either citizen or EMT.

Table 3 Factors associated with 1-Y survival of all OHCAs managed without ACLS procedures.

* Multiple logistic regression analysis.

** CPR first performed by either citizen or EMT.

CI: confidence interval. 
Table 1 Annual changes in FAST ${ }^{\mathrm{TM}}$ installation, traffic conditions, and critical parameters

\begin{tabular}{|c|c|c|c|c|c|c|c|c|}
\hline \multirow{2}{*}{$\begin{array}{l}\text { Fiscal } \\
\text { year }\end{array}$} & \multirow{2}{*}{$\begin{array}{l}\text { Total length of } \\
\text { FAST }^{\mathrm{TM}} \text { - } \\
\text { implemented } \\
\text { roads }(\mathrm{km})\end{array}$} & \multirow{2}{*}{$\begin{array}{l}\text { Number of } \\
\text { ambulances } \\
\text { equipped with } \\
\text { FAST }^{\mathrm{TM}} \\
\text { beacon unit* }\end{array}$} & \multirow{2}{*}{$\begin{array}{l}\text { Traffic volume, } \\
\text { median } \\
\text { (cars/day) }\end{array}$} & \multirow{2}{*}{$\begin{array}{l}\text { Number of OHCAs } \\
\text { (Dispatch with } \\
\text { FAST }^{\mathrm{TM}} \text {-equipped } \\
\text { ambulances/total), } \\
\text { N (\%) }\end{array}$} & \multicolumn{2}{|c|}{ Prehospiral ACLS } & \multirow{2}{*}{$\begin{array}{l}\text { Response time, } \\
\text { second (25-75\%) }\end{array}$} & \multirow{2}{*}{$\begin{array}{c}\text { 1-Y survival rate, } \\
\text { N (\%) }\end{array}$} \\
\hline & & & & & $\begin{array}{l}\text { Tracheal } \\
\text { intubation, } \\
\mathrm{N}(\%)\end{array}$ & $\begin{array}{l}\text { Epinephrine } \\
\text { administration, } \\
\mathrm{N}(\%)\end{array}$ & & \\
\hline 2003 & 2.3 & 0 & 1440 & 22/138 (15.9\%) & 0 & 0 & $360(240-480)$ & $1(0.7 \%)$ \\
\hline 2004 & 6.0 & 1 & 1368 & 45/128 (35.2\%) & $5(3.9 \%)$ & 0 & $300(240-420)$ & $6(4.7 \%)$ \\
\hline 2005 & 8.9 & 2 & 1444 & $51 / 127$ (40.2\%) & 18 (14.2\%) & 0 & $360(240-480)$ & $4(3.1 \%)$ \\
\hline 2006 & 12.6 & 2 & 1431 & 100/130 (76.9\%) & 15 (11.5\%) & $6(4.6 \%)$ & $360(240-420)$ & 7 (5.4\%) \\
\hline 2007 & 12.6 & 2 & 1393 & 104/141 (73.8\%) & 12 (8.5\%) & 8 (5.7\%) & $293(234-400)$ & $9(6.4 \%)$ \\
\hline 2008 & 12.6 & 3 & 1379 & 105/135 (77.8\%) & 35 (25.9\%) & $6(4.4 \%)$ & 340 (269-428) & $10(7.4 \%)$ \\
\hline 2009 & 12.6 & 3 & 1376 & 131/192 (68.2\%) & 31 (16.1\%) & 23 (12.0\%) & $386(280-500)$ & $5(2.6 \%)$ \\
\hline 2010 & 12.6 & 3 & 1395 & 129/170 (75.9\%) & 19 (11.2\%) & 34 (21.8\%) & 377 (301-485) & 14 (8.2\%) \\
\hline Statics & Undefined & Undefined & $\begin{array}{l}\text { One-way } \\
\text { ANOVA }\end{array}$ & $\begin{array}{l}\text { Chi-squared analysis } \\
\text { with Pearson’s } \\
\text { correction }\end{array}$ & $\begin{array}{r}\text { Chi-square } \\
\text { Pearson' }\end{array}$ & $\begin{array}{l}\text { nalysis with } \\
\text { orrection }\end{array}$ & $\begin{array}{c}\text { Kruskal-Wallis } \\
\text { test }\end{array}$ & $\begin{array}{c}\text { Chi-squared analysis } \\
\text { with Pearson's } \\
\text { correction }\end{array}$ \\
\hline$p$ & & & $<0.0001$ & $<0.0001$ & $<0.0001$ & $<0.0001$ & $<0.0001$ & 0.0360 \\
\hline
\end{tabular}

* At the beginning of fiscal year. 
Table 2 Differences in backgrounds, time factors, and the management of OHCAs between the dispatch with

FAST $^{\mathrm{TM}}$ - and non-FAST ${ }^{\mathrm{TM}}$-equipped ambulances

\begin{tabular}{|c|c|c|c|}
\hline & $\begin{array}{l}\text { Dispatch with } \\
\text { FAST }^{\mathrm{TM}} \text {-equipped } \\
\text { ambulances }\end{array}$ & $\begin{array}{l}\text { Dispatch with } \\
\text { non- FAST }^{\mathrm{TM}} \text {-equipped } \\
\text { ambulances }\end{array}$ & $\begin{array}{l}\text { Wilcoxon or } \\
\text { chi-squared test }\end{array}$ \\
\hline Number & 687 & 474 & \\
\hline Etiology: cardiac, N (\%) & 317 (46.1\%) & $235(49.6 \%)$ & 0.2493 \\
\hline Arrests: witnessed, N (\%) & 320 (46.6\%) & $219(46.2 \%)$ & 0.8993 \\
\hline Location: home, N (\%) & 449 (65.4\%) & $276(58.2 \%)$ & 0.0137 \\
\hline CPR before arrival, N (\%) & $371(54.0 \%)$ & $250(52.7 \%)$ & 0.6722 \\
\hline Age, median (25-75\%) & $75(60-83)$ & $76(61-84)$ & 0.3591 \\
\hline Sex: female, N (\%) & 256 (37.3\%) & $210(44.3 \%)$ & 0.0162 \\
\hline $\begin{array}{l}\text { Collapse/arrest } \\
\text { recognition-call (min), } \\
\text { median (10-25-75-90\%) }\end{array}$ & $2(0-1-4-10)$ & $2(0-0-4-10)$ & 0.0534 \\
\hline $\begin{array}{l}\text { Response time (s), } \\
\text { median (10-25-75-90\%) }\end{array}$ & $\begin{array}{l}327 \\
(197-244-429-571)\end{array}$ & $\begin{array}{l}381 \\
(238-291-487-704)\end{array}$ & $<0.0001$ \\
\hline $\begin{array}{l}\text { Response time }<300 \mathrm{~s} \text {, } \\
\mathrm{N}(\%)\end{array}$ & 262/687 (38.1\%) & $123 / 474(25.9 \%)$ & $<0.0001$ \\
\hline $\begin{array}{l}\text { Call-first CPR* (min), } \\
\text { median (10-25-75-90\%) }\end{array}$ & $3(-1-0-7-9)$ & $4(-2-0-7-10)$ & 0.3328 \\
\hline $\begin{array}{l}\text { Duration of transportation to } \\
\text { hospitals (s), } \\
\text { median (10-25-75-90\%) }\end{array}$ & $\begin{array}{l}420 \\
(224-300-558-718)\end{array}$ & $\begin{array}{l}420 \\
(240-300-600-810)\end{array}$ & 0.0768 \\
\hline Tracheal intubation, N (\%) & $102(14.8 \%)$ & $33(7.0 \%)$ & $<0.0001$ \\
\hline $\begin{array}{l}\text { Epinephrin administration, } \\
\mathrm{N}(\%)\end{array}$ & $64(9.3 \%)$ & $16(3.4 \%)$ & $<0.0001$ \\
\hline
\end{tabular}

* CPR first performed by either citizen or EMT. 
Table 3 Factors associated with 1-Y survival of all OHCAs managed without ACLS procedures

\begin{tabular}{|c|c|c|c|c|c|}
\hline \multirow[t]{3}{*}{ Factors } & \multicolumn{2}{|c|}{ 1-Y survival } & \multirow[t]{3}{*}{$p$} & \multirow{3}{*}{$\begin{array}{c}\text { Odds ratio } \\
(95 \% \mathrm{CI})\end{array}$} & \multirow{3}{*}{$\begin{array}{l}\text { Adjusted odds ratio* } \\
\qquad(95 \% \mathrm{CI})\end{array}$} \\
\hline & \multirow{2}{*}{$\begin{array}{c}\text { Yes } \\
\mathrm{N}=49\end{array}$} & \multirow{2}{*}{$\begin{array}{c}\text { No } \\
\mathrm{N}=909\end{array}$} & & & \\
\hline & & & & & \\
\hline Dispatch with & 37 & 493 & 0.0035 & 2.602 & 3.077 (1.180-9.350) \\
\hline $\begin{array}{l}\mathrm{FAST}^{\mathrm{TM}} \text {-equipped } \\
\text { ambulance, } \mathrm{N}(\%)\end{array}$ & $(75.5 \%)$ & $(54.2 \%)$ & \multicolumn{2}{|c|}{ ambulance, N (\%) } & \\
\hline \multicolumn{3}{|l|}{ Ambulance team, $\mathrm{N}$} & 0.1848 & & \\
\hline Ekinishi EMS & 9 & 194 & & Undefined & Reference \\
\hline Chuo EMS & 15 & 215 & & Undefined & $0.814(0.308-2.051)$ \\
\hline Misogura EMS & 17 & 240 & & Undefined & $0.461(0.175-1.143)$ \\
\hline Izumino EMS & 8 & 260 & & Undefined & $0.394(0.091-1.604)$ \\
\hline Patient age (years), & 63 & 74 & 0.0003 & Undefined & 0.976 \\
\hline median (25-75\%) & $(48-73)$ & $(60-83)$ & & & $(0.962-0.990)$ \\
\hline \multirow[t]{2}{*}{ Patient sex: female, N (\%) } & 15 & 372 & 0.1519 & 1.579 & 0.933 \\
\hline & $(30.6 \%)$ & $(40.9 \%)$ & & $(0.843-2.924)$ & $(0.467-1.803)$ \\
\hline \multirow[t]{2}{*}{ Location: home, N (\%) } & 23 & 569 & 0.0280 & 0.529 & 0.633 \\
\hline & $(46.9 \%)$ & $(62.6 \%)$ & & $(0.297-0.941)$ & $(0.337-1.186)$ \\
\hline \multirow[t]{2}{*}{ Arrest: witnessed, N (\%) } & 42 & 400 & $<0.0001$ & 7.635 & 6.798 \\
\hline & $(85.7 \%)$ & $(44.0 \%)$ & & (3.394-17.176) & (3.125-17.061) \\
\hline \multirow[t]{2}{*}{ Etiology: cardiac, N (\%) } & 33 & 442 & 0.0107 & 2.179 & 2.593 \\
\hline & $(67.4 \%)$ & $(48.6 \%)$ & & $(1.183-4.015)$ & $(1.366-5.130)$ \\
\hline CPR before EMT arrival, & 29 & 461 & 0.2480 & 1.409 & 1.603 \\
\hline N (\%) & $(59.2 \%)$ & $(50.7 \%)$ & & $(0.786-2.528)$ & $(0.754-3.119)$ \\
\hline Collapse/arrest & 2 & 2 & 0.8312 & Undefined & 0.983 \\
\hline $\begin{array}{l}\text { recognition-call (min), } \\
\text { median (25-75\%) }\end{array}$ & $(1-3)$ & $(1-4)$ & & & $(0.943-1.013)$ \\
\hline Response time (s), & 284 & 357 & 0.0010 & Undefined & 0.998 \\
\hline median (25-75\%) & $(240-343)$ & $(253-472)$ & & & $(0.996-1.000)$ \\
\hline Call-first CPR ${ }^{* *}$ (min), & 1 & 4 & 0.0877 & Undefined & 0.999 \\
\hline median (25-75\%) & $(0-6)$ & $(0-7)$ & & & $(0.940-1.005)$ \\
\hline Transportation to hospitals & 397 & 420 & 0.2679 & Undefined & 0.999 \\
\hline (s), median (25-75\%) & $(300-486)$ & $(300-552)$ & & & $(0.999-1.001)$ \\
\hline Traffic volume estimated & 1376 & 1376 & 0.1281 & Undefined & 1.007 \\
\hline from Table 1, cars/day, & $(1341-1395)$ & $(1341-1395)$ & & & $(0.996-1.019)$ \\
\hline$(25-75 \%)$ & & & & & \\
\hline
\end{tabular}

* Multiple logistic regression analysis. $\quad * *$ CPR first performed by either citizen or EMT. CI: confidence interval. 


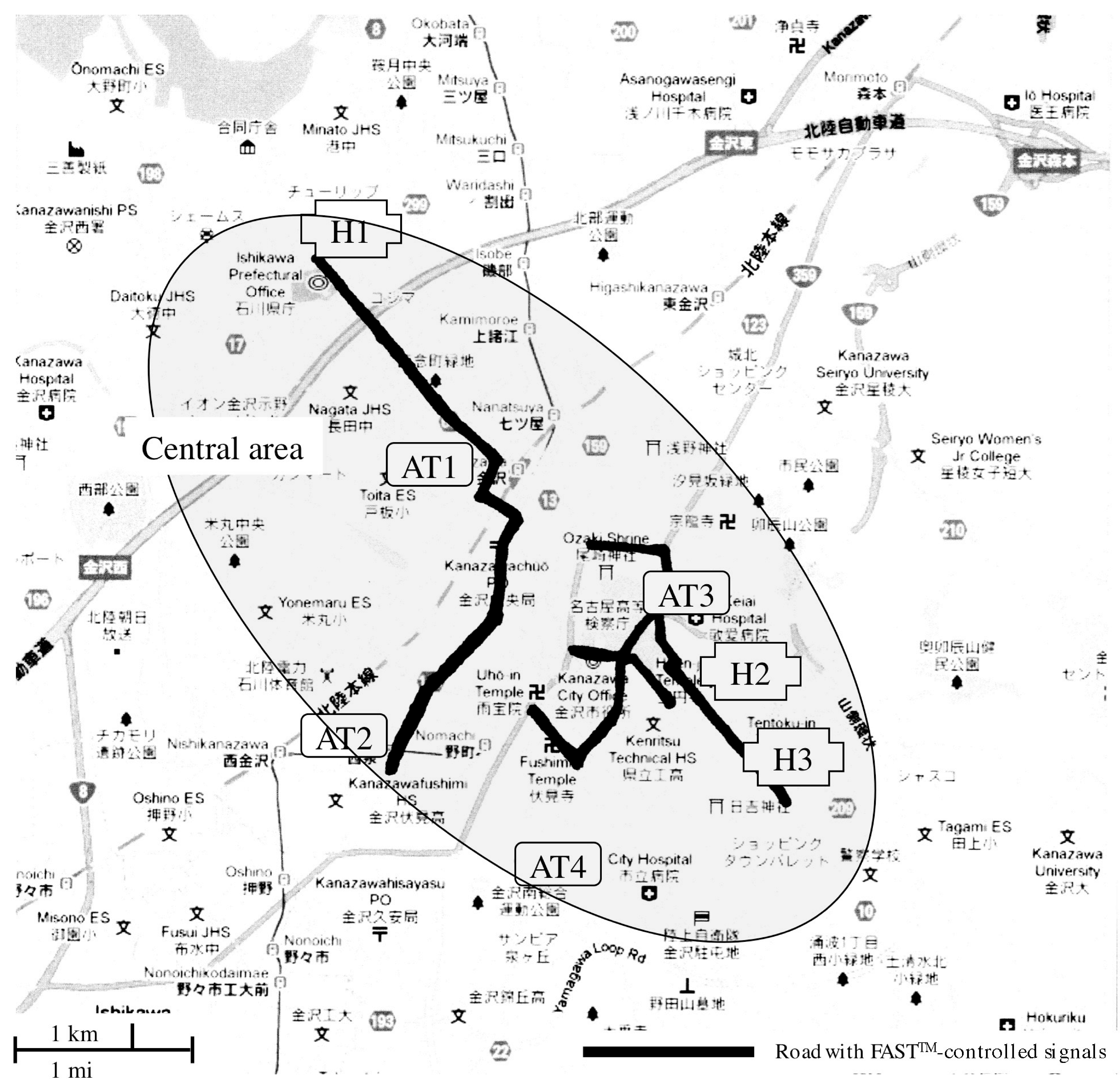



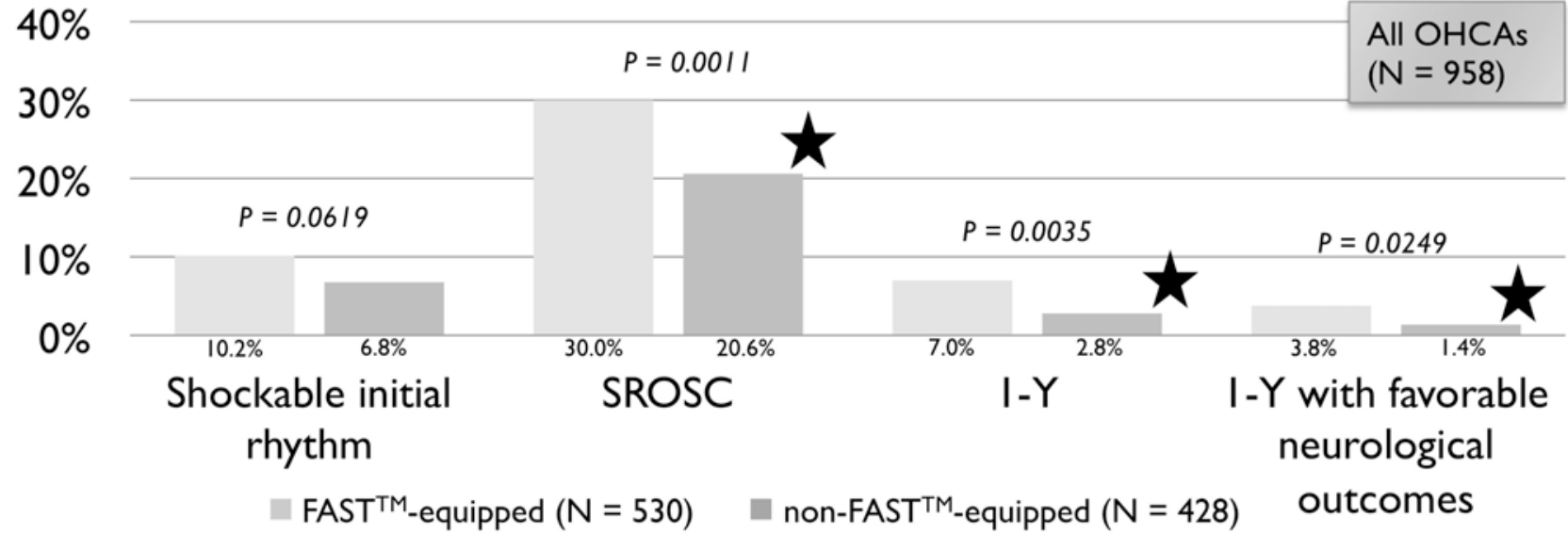

$40 \%$
$30 \%$
$20 \%$
$10 \%$
$0 \%$

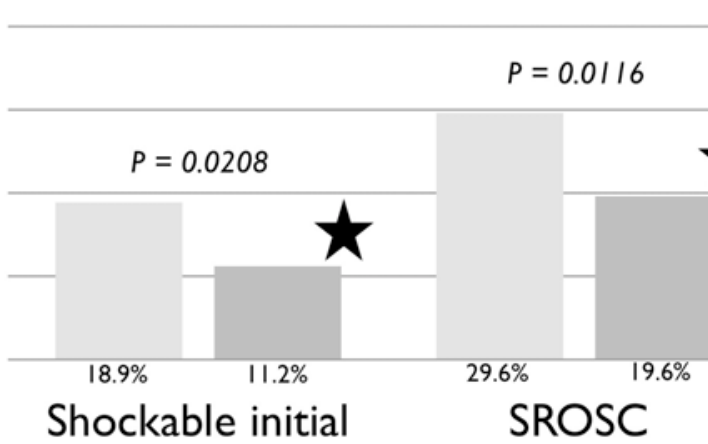

rhythm

FAST $^{\text {TM-equipped }}(\mathrm{N}=260)$
OHCAs with a presumed cardiac etiology $(N=475)$

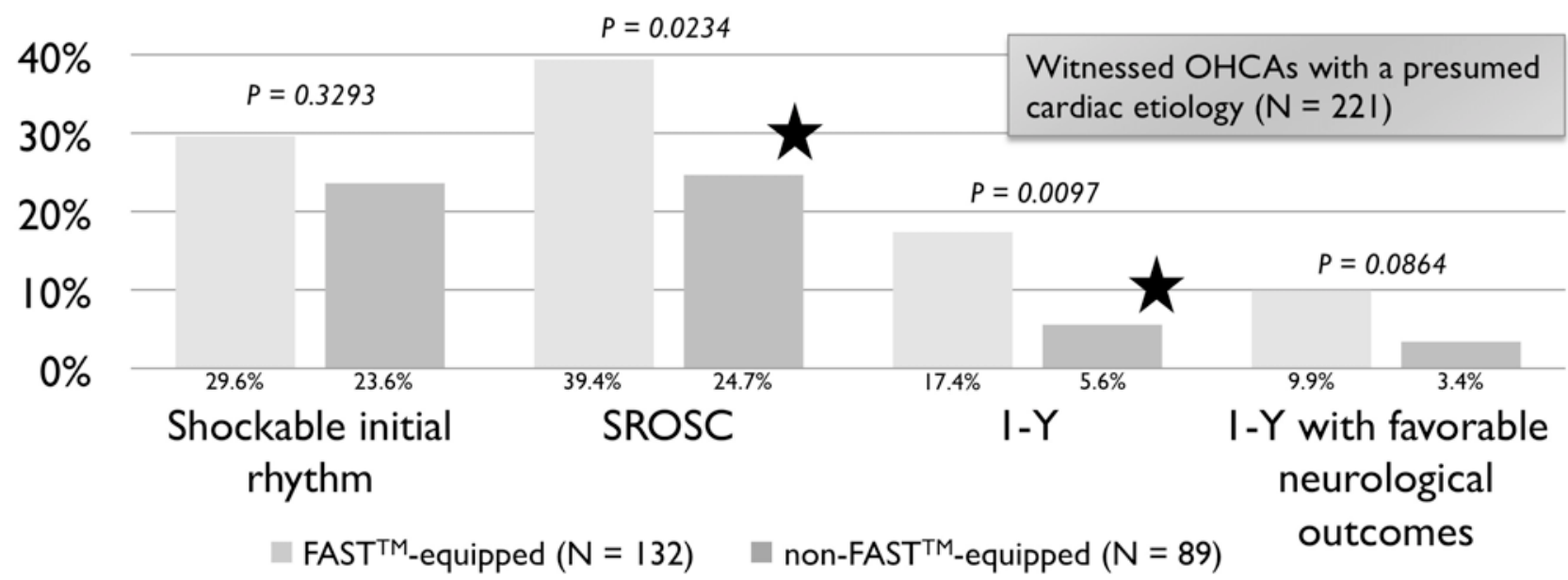

